\title{
CORRECTION
}

\section{Correction to: Total analysis of clinical factors for surgical success of adenotonsillectomy in pediatric OSAS}

\author{
Ting-So Chang ${ }^{1}$ [ $\cdot$ Rayleigh Ping-Ying Chiang ${ }^{1,2,3,4,5}$
}

Published online: 1 February 2018

๑) Springer-Verlag GmbH Germany, part of Springer Nature 2018

\section{Correction to: \\ Eur Arch Otorhinolaryngol (2017) 274:561-566 \\ https://doi.org/10.1007/s00405-016-4218-8}

The authors would like to publish this erratum to indicate Dr Rayleigh Ping-Ying Chiang as the corresponding author of this article.

Ting-So Chang

spicychang@hotmail.com

1 Department of Otolaryngology Head and Neck Surgery, Taipei Veteran General Hospital, No.201, Shipai Rd. Sec.2, Taipei, Taiwan, ROC

2 Center of Sleep Medicine, Taipei Veteran General Hospital, Taipei, Taiwan

3 Department of Otolaryngology, School of Medicine, College of Medicine, Taipei Medical University, Taipei, Taiwan

4 International Sleep Science and Technology Association, Berlin, Germany

5 Sleep Technology Consortium, Ministry of Science and Technology, Taipei, Taiwan 